\title{
Stabilisation of progressive idiopathic scoliosis in the period of maturation in girls treated using Dobosiewicz's method (period of the observation $>36$ months)
}

\author{
Jacek Durmala*1, Krystyna Dobosiewicz ${ }^{2}$ and Jerzy Piotrowski ${ }^{1}$
}

Address: ${ }^{1}$ Department of Rehabilitation, Medical University of Silesia, Katowice, Poland and ${ }^{2} \mathrm{GWSH}$, Katowice, Poland

Email: Jacek Durmala* - jdurmala@gcm.pl

* Corresponding author

from 4th International Conference on Conservative Management of Spinal Deformities

Boston, MA, USA. 13-16 May 2007

Published: 12 October 2007

Scoliosis 2007, 2(Suppl I):S5 doi:I0.II86/I748-7|6I-2-SI-S5

This abstract is available from: http://www.scoliosisjournal.com/content/2/SI/S5

(c) 2007 Durmala et al; licensee BioMed Central Ltd.

\section{Objective}

The aim of the study was the retrospective analysis of effectiveness of conservative treatment of progressive idiopathic scoliosis (IS) in the period of maturation.

\section{Study design}

The analysis included twenty girls with IS (thirty-one curves; eleven double major, six thoracic, three thoracolumbar). The mean initial Cobb angle was $27.7 \pm 7.52$ degrees (range 15-45 degrees). Progression was defined as radiological documentation of a $>6$ degree increase in Cobb angle in six months. All patients were treated using Dobosiewicz's method [1-5]. The criteria of inclusion was a minimum observation period of $>36$ months spanning one year before and after first menstruation, with hospitalization at least two times in the Department of Rehabilitation. The mean duration of observation was $50.9 \pm 16.7$ months (range 37-91 months). Patient compliance was not taken into account in this analysis.

\section{Results}

Mean progression of Cobb angle in the study group was $0.6 \pm 6.45$ degrees (range -14 to $+15^{\circ}$ ). Mean progression of AVR angle was $1.0 \pm 5.76$ degrees (range -15 to $+15^{\circ}$ ).

\section{Conclusion}

The radiological results demonstrated prevalent stabilisation of scoliotic curves in girls with progressive IS, treated using Dobosiewicz's method.

\section{References}

I. Durmala J, Dobosiewicz K, Kotwicki T, Jendrzejek H: Influence of asymmetric mobilisation of the trunk on the Cobb angle and rotation in idiopathic scoliosis in children and adolescents. Ortop Traumatol Rehabil 2003, 5:80-85.

2. Dobosiewicz K, Durmala J, Kotwicki T: Biodynamic method for 3 $D$ correction of idiopathic scoliosis: a description of the method. Ortop Traumatol Rehabil 2005, 28:49-54.

3. Dobosiewicz K, Durmala J, Czernicki K, Piotrowski J: Radiological results of Dobosiewicz method of three-dimensional treatment of progressive idiopathic scoliosis. Stud Health Technol Inform 2006, I 23:267-272.

4. Dobosiewicz K, Durmala J, Czernicki K, Jendrzejek H: Pathomechanic basics of conservative treatment of progressive idiopathic scoliosis according to Dobosiewicz method based upon radiologic evaluation. Stud Health Technol Inform 2002, 91:336-34I.

5. Dyner-Jama I, Dobosiewicz K, Niepsuj K, Niepsuj G, Jedrzejewska A, Czernicki K: Effect of asymmetric respiratory exercise therapy on respiratory system function; evaluation using spirometric examination in children with idiopathic scoliosis. Wiad Lek 2000, 53:603-6I0. Polish 